\title{
Corporate-Level Communities at Ericsson: Parallel Organizational Structure for Fostering Alignment for Autonomy
}

\author{
Darja Šmite $^{1(\bowtie)}$, Nils Brede Moe ${ }^{1,2}$, Jonas Wigander ${ }^{3}$, \\ and Hendrik Esser ${ }^{3}$ \\ ${ }^{1}$ Blekinge Institute of Technology, Karlskrona, Sweden \\ Darja.Smite@bth. se \\ 2 SINTEF, Trondheim, Norway \\ ${ }^{3}$ Ericsson, Stockholm, Sweden
}

\begin{abstract}
Organizational management traditionally has taken care of all the important strategy, structure, and work-design decisions, as well as most of the ongoing decisions about work procedures. In large-scale corporations with many geographically distributed sites and high divisional detachment, such strategies are yet doomed to result in implementing irrelevant work methods and procedures that conflict with the local interests. As Tayloristic habits are disappearing, organizations willingly or unwillingly change their decision-making approaches to enable more participation and influence from the performers. These trends are associated with the rise of participation-based parallel structures, such as quality circles, task forces or communities of practice. In this paper, we present our findings from studying corporate-level communities by the means of a multicase study at Ericsson. We found that the main hindrances are related to the limited decision-making authority of parallel structure, member selection and achieving representation across the organizational units. Our results suggest that parallel structures highly depend on the authority of the members within their local communities, and their ability to not only channel the dialog between the units they represent and the community, but also enable the active engagement of the unit in the community studies. As such, we believe that special attention shall be put on the ambassador role of the community members.
\end{abstract}

Keywords: Large-scale agile $\cdot$ Organizational agility ·

Bottom-up governance $\cdot$ Communities $\cdot$ Parallel structures $\cdot$

Alignment for autonomy $\cdot$ Empirical

\section{Introduction}

The sweet spot of agile methods is small-scale software development, and the vast majority of agile methods are intended to improve efficiency and effectiveness of small agile teams. Yet, adoption of agile principles on a corporate level and for large-scale contexts is gaining a lot of attention [1]. The paradigm shift towards increased agility on all levels in the organization has motivated major organizational transformations and puts the traditional hierarchical view on decision-making in question. In fact, along 
with agile transformations on the development levels, large organizations are increasingly adopting alternative organizational models to circumvent the challenges of traditional hierarchies, top-down management structures, and centralized decisionmaking, and focus on self-management, autonomy and decision-making as a shared process, even though these efforts are associated with many challenges [2-4].

To become more flexible, large-scale organizations seek new ways to combat their inefficiencies. Centralized decisions in large organizations significantly slow down decision-making, and, to function faster, such organizations increase autonomy through decentralization at the divisional level, while keeping the technostructure at corporate headquarters [5]. However, such work systems are often associated with divisional detachment and increased coordination challenges [6], as well as varying quality and efficiency across the different units. It is not uncommon that different organizational units simultaneously would spend effort on attacking the same problems, or in the worst case even developing competing products. Thus, large organizations often depend on their ability to standardize the outputs and process [5] through coordination and alignment.

In a large-scale agile organization, where work is organized in programs and teams situated in different geographic locations and often belonging to different organizational units, there is a need to align a lot of decisions, e.g. the vision, mission and strategy, development tools to use, methods and processes. Standardizing the processes and tools will also help the organization in keeping track of the state of practice across the organization, to share good practices and knowledge across the organizational units. At the same time, rigid control impairs necessary local optimizations and ability to see creative solutions to local problems [7]. To succeed, organizational units need the freedom to choose the best processes and tools to solve their problems in their particular context. This leads to a paradoxical challenge of how to standardize as little as possible to benefit from organizational alignment and not impair the autonomy and flexibility.

One of the known answers to this challenge is fostering organization-wide participation in leading the alignment efforts with the means of structures parallel to the traditional organization. Parallel structures are permanent or temporary structures that are established to supplement the regular organization by performing functions that it does not perform or is ill-suited to perform well [8]. Some examples of parallel structures include quality circles [9] and communities of practices [10]. In this paper, we present our findings from studying corporate level communities in Ericsson, a large international company headquartered in Sweden, one of the worldwide leaders in the telecommunication market. Ericsson can be seen as an organization compound of many geographically distributed research and development centers united in thirteen product development units (each of which may include multiple geographic locations). Ericsson has started the World Class Development program in 2014 to improve the ways of working across the whole organization, and multiple workgroups were created to formulate corporate-level strategies and standards within selected subject areas. Members for the work groups were chosen from different parts of the organization, to find ideas and solution candidates already existing in the organization, and to increase the buy-in. These work groups were coordinated by the Software Systems community, 
the first corporate-level community that later initiated the transformation of the shortterm working groups into long term communities that support the organizational units in the deployment of established standard approaches, and lead the continuous improvement of these standard approaches.

As a form of parallel organizations, communities have their strengths and weaknesses. Lawer and Mohrman [9] have observed that such company-wide mechanisms are said to attract a lot of attention and enthusiasm in their startup phases but then require significant effort to sustain them over several years. Similarly, not all Ericsson communities turned out successful in the long run. A few years after the implementation of the parallel structures, the community leaders recognized that achieving an agreement and commitment to the concept of corporate communities across the organization is challenging. The organization continuously changes and the community leaders have to keep all the managers from different organizational units aware of the community mission and work. This was challenging because collaboration over boundaries in a fragmented organization is a very formidable task, and because this initiative is still looked at as being driven from "above". Our research is thus driven by the need to better understand what makes or breaks the implementation of parallel organizational structures that are introduced to increase the agility in the large. In our research we thus aim at answering the following questions:

RQ1: What hinders participation-based parallel structures in a large-scale distributed agile organization?

RQ2: How to strengthen such parallel structures to maximize their benefits?

The rest of the paper is organized as follows. In Sect. 2, we summarize the existing research related to the participatory mechanisms for organizational alignment. Section 3 outlines the empirical background of our work, and the applied research methodology. Section 4 contains the results, which are discussed in Sect. 5, followed by conclusions in Sect. 6.

\section{Related Work}

Parallel organizational structures can be seen as a part of corporate governance, elements of the system relating to the management and control of an organization. As a governance structure, it should specify the distribution of rights and responsibilities, and arrange the rules and procedures governing decision-making processes. Although the area of organizational governance is a well-developed research field, studies on participation-focused parallel structures used for governance tasks in large-scale agile software organizations are scarce.

Participation and involvement have been one of the most important foundations of organizational development and change and has always been a central goal and one of the pillars of organizational learning [11]. When members of an organization feel they are excluded from participation by the leadership, they will find ways, often unhealthy, to express themselves [12]. Participation is also highly valued in software companies [13] and specifically in agile software development. Therefore, organizations need to provide a climate of participation if they are to remain healthy. By doing so, they 
increase not only the learning capacity of employees, but also their ability to influence organizational outcomes. Another potential effect of participation is increased emotional attachment to the organization, resulting in greater commitment, motivation to perform and desire for responsibility. As a result, employees care more about their work, which may lead to greater creativity and helping behavior, higher productivity and service quality [14]. However, participation is a challenge when the scale is large, even in agile organizations, where thousands of developers are scattered across multiple locations. Further, participation itself does not ensure that an organization will be successful in achieving its goals, and participation includes some degree of risk, as seen by management. For participation to be successful, the members of an organization must know how to participate effectively [12].

So, how does a large-scale agile organization achieve participation? Several techniques have been proposed to foster participation in organizations. Cotton et al. [15] found that long-term forms of participation appear to be more effective than short-term forms. For example, search conferences [16], survey feedback [17], autonomous work groups [18], quality circles [9, 18], process workshops [19], and learning meetings [20] are all predicated on the belief that increased participation will lead to better solutions and an enhanced organizational problem-solving capability.

Self-organizing groups that transcend official organizational structures have proven to be key enablers for success in the kinds of environments, where top-down organizational alignment, standardization and control are unwanted or difficult to operate [2]. A quality circle, for example, is an organizational structure composed of volunteers who arrange regular meetings to look at productivity and quality problems and discuss work procedures [9]. The strength of such circles is that they allow employees to deal with improvement issues that are not dealt with in a regular organization. The solutions proposed by the quality circles may or may not be implemented by the organization [18], since they are formulated as recommendations further discussed with and approved by the management. As such quality circles have a participatory rather than delegated decision-making [9]. Similarly, communities of practice that are traditionally suggested for their ability to foster knowledge sharing within an organization, and help individuals expand skills and expertise [21, 22], are also cultivated for their potential to help organizations improve coordination and standardization across units [10].

Both quality circles and communities of practice are well researched parallel structures. There are also examples of related research in the context of large-scale agile, including project level communities such as communities used for inter-team coordination in an agile program [23], communities using open space technology as a participation technique similar to a search conference [16] that served as a forum to discuss challenges and improvement initiatives [24], experience forums focusing on improving the development methods in a large-scale program [25] and communities that primarily target knowledge culture in organizations [22]. At the same time, corporate-level structures especially in the large-scale agile context are not well understood. Lawer and Mohran [9] mention task forces that broaden the quality circle structure by including the authority to look into policies, organizational design and other organizational issues. Kahkonen proposed three agile methods developed at Nokia that use facilitated workshops to solve multi-team issues and cultivate 
communities of practice that amass people from different parts of organizations to perform a specific well-defined task [2].

Finally, it is fair to assume that research proposing recommendations for wellfunctioning parallel structures enabled on the operational level such as the task forces, quality circles and communities of practice, are also applicable on a corporate level. According to Lawer and Mohran [9] and Wenger et al. [10], to succeed with the implementation of parallel structures, an organization shall pay attention to:

- Designing the existing organization to support the parallel structure by ensuring the needed decision-making authority and means of getting the needed support in implementing decisions;

- Involving a broad part of the organization by allowing open participation of various forms and promoting a high level of participation and representativeness across the organizational units;

- Delivering the value for the organization and the participants. This often means that a parallel structure shall be equipped with the competence needed to make good suggestions and decisions from practical and economic points of view, taking into account overall strategy and business objectives;

- Ensuring the visibility of the achieved results and value created for everyone.

\section{Research Methodology}

Since the goal of this research is to explore and provide insight into the participationbased parallel organizational structures in large-scale agile software development, it is important to study such structures in practice. In this study, the focal point is corporatelevel communities that are introduced to improve work processes, methods and tools in the areas of organizational importance, where coordination and alignment across organizational units is seen as a source of performance and cost benefits.

To address our research questions, we designed a holistic multiple-case study [25] of seven communities in one company, Ericsson, which had been using agile for more than 10 years. According to Yin, case studies are the preferred research strategy when a "...question is being asked about a contemporary set of events over which the investigator has little or no control" [25].

Our sample contained seven out of eight communities; all available for study (C1C7, see Table 1). Our research was performed in two steps. First, we contacted community leaders to learn and describe how the corporate level communities operate (October 2017). Then, we performed a detailed study of two selected communities focusing on the challenges and improvement recommendations from the point of view of the community members (November 2017 - March 2018).

\subsection{Data Collection}

In the first step, we interviewed the leaders of all seven communities. We conducted eight semi-structured interviews (one leader was interviewed twice), which aimed at capturing community's mission, authority, membership and repertoire. All interviews 
were approximately $1 \mathrm{~h}$ long, conducted in English and recorded with the help of AudioNote. Most of these interviews were held in person, but some via Skype due to unavailability of the interviewees in the office.

Based on the first step, leaders of two communities (C3 and C5, see Table 1) volunteered for detailed analysis, during which the researchers observed online community meetings and interviewed community members. In both $\mathrm{C} 3$ and $\mathrm{C} 5$, we started by interviewing the leader (one in C3 and 2 interviews with the leader of C5). The leaders helped us select six members (passive, active and new) for further interviews. We also observed community meetings at two occasions in each of the communities and wrote detailed minutes. All interviews in the second stage were held electronically via Skype, conducted in English and recorded with the help of AudioNote.

\subsection{Data Analysis}

The data collected from 23 interviews and four observations was analyzed in iterations. All interviews were recorded using AudioNote which is a tool for writing notes during the recording. The notes are then connected to the actual part of the interview. During the data analysis, we listened to the interviews and extended the notes. Through our engagement with the data, the success criteria for implementing organizational parallel structures emerged as an appropriate lens for examining participation in a large-scale agile setting. Thus, when analyzing the data, we used the success criteria from related research [9] as input and sought to understand the hindrances.

When analyzing the data, we relied on data source triangulation. Our rationale for the choice of interviews, observations and documentation as data sources for the study of communities as an example of participation and parallel organization is that by interviewing members, we gained access to their own understanding of the communities. Analyzing the observations and documentation shed light on the reasons given by the interviewees and provided context to their statements. As such, data triangulation is likely to have strengthened our findings and conclusions by increased accuracy.

\section{Results}

In this section, we describe our results from studying corporate-level communities at Ericsson and how they enable organizational agility and participation in a large-scale distributed organization. As described in the related work, to succeed with the implementation of parallel structures, an organization shall pay attention to $[9,10]$ :

- Ensuring the needed authority;

- Involving a broad part of the organization;

- Supporting value creation for the organization and the participants;

- Ensuring visibility of the achieved results for everyone in the organization.

In the following, we describe how the studied communities are set up (see Table 1), their mission and scope, and how they operate according to the above success criteria, and what are the main hindrances. 


\subsection{Mission and Scope}

Ericsson has started their agile transformation more than 10 years prior to our investigation. However, the maturity of the new ways of working significantly differs across the organizational units and geographic locations. Corporate-level communities were implemented partly to support the agile transformation and the acceptance of the agile principles, and partially to foster the participative culture across the organization. Each of the studied communities focused on a selected strategic area (see Table 1). The prime purpose of these communities can be seen as standardization [27]. As an interviewee described: "When we got 100 [agile] teams in eight countries we need to agree on some common tools". Based on a high level of participation, communities are responsible for keeping track of the state of practice across the organization, communicate the corporate strategy, get feedback on the feasibility of the needed changes, enable autonomy and support the units in their efforts towards alignment. As explained by an interviewee "It is about just-enough alignment, maximum autonomy and maximum participation.... We call it a self-organizing eco-system”.

Table 1. Overview of the studied communities. " $X$ " in the table denotes characteristics present in a community.

\begin{tabular}{|c|c|c|c|c|c|c|c|}
\hline & $\mathrm{C} 1$ & $\mathrm{C} 2$ & $\mathrm{C} 3$ & $\mathrm{C} 4$ & $\mathrm{C} 5$ & C6 & $\mathrm{C} 7$ \\
\hline \multicolumn{8}{|l|}{ Mission and scope } \\
\hline $\begin{array}{l}\text { - Strategy } \\
\text { development }\end{array}$ & & & & $\mathrm{X}$ & $\mathrm{X}$ & & $\mathrm{X}$ \\
\hline - Status monitoring & $\mathrm{X}$ & & $\mathrm{X}$ & $\mathrm{X}$ & $\mathrm{X}$ & & \\
\hline - Knowledge sharing & $\mathrm{X}$ & $\mathrm{X}$ & $\mathrm{X}$ & $\mathrm{X}$ & $\mathrm{X}$ & $\mathrm{X}$ & $\mathrm{X}$ \\
\hline \multicolumn{8}{|l|}{ Authority } \\
\hline - Unclear & & $\mathrm{X}$ & & & & & \\
\hline \multicolumn{8}{|l|}{ Membership } \\
\hline - Open & $\mathrm{X}$ & $\mathrm{X}$ & $\mathrm{X}$ & & & $\mathrm{X}$ & $\mathrm{X}$ \\
\hline - By appointment & $\mathrm{X}$ & & $\mathrm{X}$ & $\mathrm{X}$ & $\mathrm{X}$ & & $X$ \\
\hline - No of members & 30 & $30-40$ & 13 & 31 & 30 & $30+$ & $25-30$ \\
\hline \multicolumn{8}{|l|}{ Representation } \\
\hline - Represented units & 10 & Unknown & 13 & 13 & 12 & 13 & 11 \\
\hline $\begin{array}{l}\text { - Unrepresented } \\
\text { regions }\end{array}$ & Asia, USA & & USA & & & $\begin{array}{l}\text { Asia, India, } \\
\text { USA }\end{array}$ & Asia, India \\
\hline
\end{tabular}

While standardization and corporate-level alignment is the essential mission of the studied communities, knowledge sharing is also an important emergent task. Most of the communities dedicate time for sharing experience across the organizational units. 
Knowledge sharing is often fostered by community leaders, who seek interesting topics and contributions from more mature units and request to demonstrate locally developed tools, practices, and lessons learned, such as the advances in continuous integration or continuous testing. This is said to be of great value for less mature organizational units.

To keep track of what is going on across the organization, discuss the needed improvements to the corporate strategies and share the knowledge across the units, the studied communities hold regular planned meetings. These meetings are on average 1,5 h long (between $30 \mathrm{~min}$ and $3 \mathrm{~h}$ ) and are typically held on a biweekly basis. Since all communities have representatives from different geographic locations, community meetings are held electronically, typically using audio channel only. Some communities happen to have several co-located members who gather in the same meeting room and connect to the rest of the members via a phone conference.

The vast majority of community meetings follow a structured agenda, proposed by the leader. From observing community meetings, we found that the meeting in one of the communities was about reporting and informing, and it's mostly the leader talking. The other observed community had more interaction and discussion.

Beside the meetings, members are required to read material before the meetings, answer questions, elicit feedback or seek approval locally in their units, prepare presentations on the status in their units, and pursue the units to engage in field studies, i.e. testing community ideas, piloting new ways of working.

\subsection{Decision-Making Authority}

We found a great variance among the corporate-level communities with respect to their decision-making authority, as well as commonly recognized challenges. First of all, we found that most of the communities make recommendations to management, based on their work, similarly to the quality circles [9] which means they do not have unlimited decision-making authority. Among seven communities, the leaders from only three communities had a strong belief they have the power to drive the strategy or change the existing standards in their areas. This means that the targeted cross-organizational alignment becomes a result of a dialog between the units, the community and the corporate management. The leaders of other communities mentioned that they either did not have the power to make certain decisions or have never used it. In some communities, the alignment directives are driven from the top down, in which case members of the community develop an action plan on how to comply with the corporate directions and follow up on the progress across the organizational units.

One particular challenge related to authority many communities face is their limited ability to implement the standards across the organization units. Some of the community recommendations might conflict with the interests of particular organizational units. As one member explained: "What is a good practice in one [organizational unit] is not a good practice in another". Since communities are not equipped with policing functions, but focus on the status gathering and support, the perceived authority of the communities to purse the organizational units is low. As such, some leaders said that when organizational units disagree with the alignment requests, they can simply not follow the community recommendations. In addition, communities cannot request the units to apply or implement their proposals, because communities do not have any 
dedicated budget, and any community-related field work ultimately depends on the ability of local representatives to find and approve the use of resources within that unit.

\section{Challenge: When corporate interests are in conflict with the local interests, community recommendations may be ignored due to a lack of formal authority.}

While some community leaders and members perceived missing a formal decisionmaking authority as a problem, others explained that the formal authority was not that important. For the parallel structure to influence the established organization, several interviews claimed that it was more important to have a dialogue with the key management in the local organizations. One community member explained: "To make a change you need to discuss [it] with management that got decision-making authority.... I therefore conducted 30 min interviews with key stakeholders in the line organization to understand their perspective and to create a good relationship. Then I use my social network to influence their decisions". This community member was successful in implementing decisions made by the community and to share knowledge from the community. He called himself a "diplomate". However, not everyone had such a strong network and were able to influence others.

Challenge: While the lack of authority can be to a degree addressed by a strong local social network, community members that are new or weakly integrated in the organizational networks are not able to have any local influence.

\subsection{Breadth of Involvement}

We found that all but one community (Software Developer community that was open to anyone) are designed to have permanent members representing each organizational unit. Some of these communities are also open for additional members. At the moment of our study, the number of community members varied from 13 to 40 with the average of 28 members. The units could be represented by one or several members and could bring guests to particular meetings. One community maintained an information channel open for subscription with over 90 subscribers.

All community leaders agree that broad involvement from the units is important for the corporate-level communities to be able to make good decisions and make sure that recommendations do not conflict with local interests of a unit. At the same time, having too many representatives can also cause challenges. Communities with too many people involved in approving ideas makes decision-making process slower. As the leader of the CI and test community explained: "The wheel is too big to turn. It can take months". To ease the process of feedback elicitation and speed up decision making, some communities publish working material in the community spaces and used Yammer ${ }^{1}$ functionality for online discussions, where the members can trace all questions and comments, and make changes before meeting and discussing the decisions.

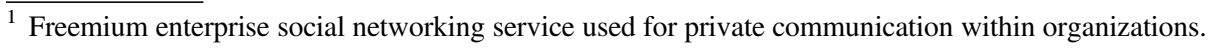




\section{Challenge: Achieving an agreement across all organizational units takes time.}

Another challenge that impacts the efficiency of decision-making is the coverage of the units in the community. Three of the studied communities reported that they do not have representatives from all units or locations. This mean that decisions taken in the community might not reflect the actual situation in the whole distributed agile organization, and that decisions need to be revisited if people of the missing units join.

Furthermore, some community leaders said that the organizational units do not always make a good selection of representatives. As the CI and test community leader explained, communities need to get the right people to represent the organizational units, and thus it is important to seek the best suited experts instead of formal appointment. These people shall have local authority and a contact network, to be able to elicit fast feedback from the unit on the decisions discussed in the community. Another community member verified this view: "How successful we are depends on who are the members and how well they are connected to the local organization".

In addition, some of the organizational units are so large (see Fig. 1) that one representative is not always aware of the processes and happenings across the whole unit he or she represents. One of the members from the CI and test community described that his unit is a merger of two different product development organizations spanning several geographical locations. Each of the product development organizations had their own methods, processes, and tools, and subsequent interests. Thus, he thought that ideally more representatives were required to represent the possibly varying interests.

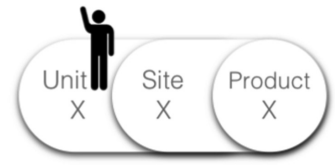

A unit develops a single product in a single site (One representative possible)

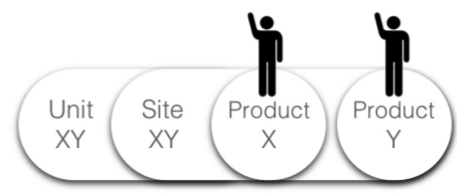

A unit develops multiple products in a single site (Representatives from all products advised)

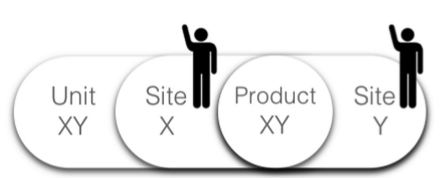

A unit develops a single product in multiple sites (Representatives from all sites advised)

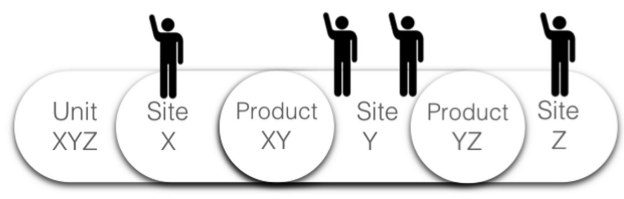

A unit develops multiple products in multiple sites (Representatives from all sites and products advised)

Fig. 1. Structures relevant for selection of unit representatives. 


\section{Challenge: Selecting one permanent member to represent an organizational unit is insufficient in large distributed units.}

The ability of communities to make the interests of particular organizational units heard was also affected by the level of attendance of the meetings. Some organizational units are represented, but the members either do not attend meetings, or remain inactive. Community leaders estimate that on average about $40 \%$ of all members participate in meetings. The community with the highest attendance reported $2 / 3$ of the members to be present regularly, while the community with least attended meetings reported about $1 / 5$ of the members. Notably, only $1 / 3$ of the members present in the meetings is said to actively engage in discussions or ask questions.

\section{Challenge: Poor attendance and activity of the members negatively influence their ability to voice the interests of particular units in the community.}

To understand what influences the level of engagement, we elicited opinions from the members of two communities. The following circumstances increased participation:

- Personal contact and familiarity among the members;

- Personal interest and competence in the topic;

- Leader's effort in engaging members.

We also learned that participation decreased when:

- Organizational unit's competence is much higher than that of others member represented units (perceived ability to learn from others is low);

- Only the leader on the agenda, so others are reluctant to engage;

- Members are new to the community and have not been properly onboarded;

- Organizational units do not prioritize or recognize community work.

\subsection{Value and Results}

We found that communities generated value on three levels - corporate level, unit level and individual level of the members. On the corporate level, the recognized benefits are primarily related to the ability of the communities to drive the execution of strategic plans, capacity for knowledge-development projects and form knowledge-based alliances, and enabling coordination, standardization and synergies across organizational units. On the unit level, the benefits seem to be twofold. For more mature units, participation in communities provides opportunities to influence the corporate strategies and promote their local advances in an area to the corporate level. Meanwhile less mature units can benefit from getting access to the advances from across the organization. Finally, on the individual level, the interviewed community members mentioned to benefit from participation in the community through the ability to deepen their understanding of the standards, find solutions to own problems and learn from others, and from networking with key experts across the organization. 


\subsection{Visibility in the Organization}

Sharing experience among units and disseminating community work results, including conclusions based on cross-unit field studies and investigations, was seen as an important mission for all communities. The main means to achieve this included communication among the members and with their local peers, communities and management, and sharing results through a community web page that is available for everyone in the company. One particular community enabled a number of means of communication with the community for the rest of the potential users (see Fig. 2): anyone accessing this web page can ask questions about the community, see the results from community work, and community plans (e.g. backlog and task list).

\section{SW DEVELOPMENT SYSTEM COMMUNITY}

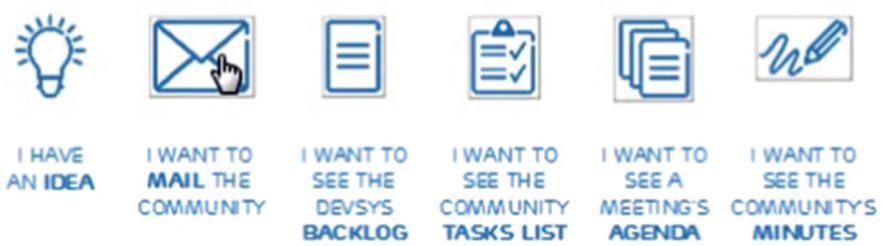

Fig. 2. A snapshot of a part of the Software Development System's community web page.

Some members complained that their communities were not well recognized or even known to their peers in respective organizational units, while others said that their communities were well-recognized for their work. We found that in many cases, the visibility of the community was again directly related to whether the individual members are well connected in their local units. One of the community members explained, "In some cases I have used own distribution lists. In other cases I go directly to persons I know are affected, sometimes I set up a meeting with whoever should be aware of [the results]... I am using the established forum where product, processes, methods and tools [-related] meetings we have, where I can present this kinds of stuff".

\section{Challenge: Community work visibility across the whole organization highly de- pends on the connections of the community members in local units' networks.}

\section{Discussion}

In this paper, we presented our findings from studying corporate-level communities by the means of a multi-case study at Ericsson. These structures at Ericsson are regarded as important elements of the self-organizing eco-system. We now discuss our results in light of our research questions: What hinders participation-based parallel structures in a large-scale distributed agile organization? and How to strengthen these parallel structures to maximize their benefits? 


\subsection{Hindrances in Corporate-Level Parallel Structures}

To understand what hinders corporate-level parallel structures at Ericsson, we have analyzed their characteristics in the light of the success factors proposed in related research $[9,10]$. A successful parallel organizational structure is said to have support from the organization in terms of the needed decision-making authority, to involve a broad part of the organization, to deliver value for the organization and the members, which is also recognized within the organization.

With respect to the organizational support, we found that not all Ericsson communities have received the needed decision-making authority. Our results suggest that some communities still act upon top-down directives, and have limited decision power, while others drive the strategy and improvements in their area. Furthermore, we found particular challenges with the ability to pursue and engage the organizational units in community studies and initiatives. Corporate support was insufficient and whenever community recommendations conflicted with the local organization, communities were perceived as a burden, as suggested in related research [9].

With respect to the involvement in the large-scale distributed context, we further found that the studied communities had a broad coverage of the organizational units. While voluntary participation is often seen as a weakness of community structures [10], mandatory unit representation ensured a reasonable representativeness, even though some units were not represented in some communities. The main challenge with respect to involvement was to sustain high levels of member participation in meetings. Similarly to related research [9] we found symptoms that the enthusiasm when the initial work groups were launched has decreased over time, and some of the previously active members have become less active. We also found that achieving a valid representation of all locations and programs in large units was important (see Fig. 1), since each might have their own work processes, tools and/or local improvement initiatives. As such, we found that the success of communities highly depends on whether the members are well connected in their local networks and the level of their awareness of what is happening across the unit they represent.

Most of the communities seemed to work successfully towards their goals, i.e. coordinated the deployment of the standards and policies supporting agile software development and balancing the corporate need for alignment and the local need for unit autonomy. As such, the organization represented by the Software Systems community, has recognized the value of enabling community-based parallel structures. The individual members also benefitted from their membership in terms of access to the knowledge and a company-wide expert network. As such, our study confirms the ability of parallel structures to create value on an organizational and individual levels $[10,21]$. Furthermore, we learned that those who seem to benefit the most from community membership were the representatives from the organizational units with less mature ways of working or limited knowledge in an area of community concern.

Finally, community leaders have complained about the lack of visibility of their results across the organization, and the lack of understanding of the value for the units. In fact, many community leaders and community members commented on the lack of dedicated time for community work given to the unit representatives (a common 
problem in communities of practice $[22,27,28]$ ), and the lack of recognition of the importance of unit representation.

\subsection{Strengthening Corporate-Level Communities}

Our findings suggest that parallel structures might be doomed to take a back seat when it comes to power and decision-making mandate in comparison with official organizational structures. Therefore, we would like to emphasize the importance of the personal authority and connections of the individual unit representatives in their local organizations. In contrast to communities of practice, in which membership is voluntary and internal structures evolve organically [10], parallel structures similar to the studied communities at Ericsson will need mandatory membership in addition to the open one, and careful selection. We believe that the key to strengthening the corporatelevel communities is related to finding ambassadors well anchored in their local organizations. Our findings suggest that even if a community would have no authority mandated by the corporate management, it would still be able to drive initiatives, if the individual unit representatives had local authority. Furthermore, it seems that the number of representatives does not matter, if the member present is well connected. This is why we believe that local authority and the amount of connections in the organizational unit's should be the prime characteristics for member selection.

At the same time, our findings suggest that member participation and unit engagement play a critical role when it comes to the value created by the communities. All of the identified benefits of the studied communities relate to learning, discussion, networking or coordinating with others. If the number of participants is low, naturally the benefits provided by participation in the community are decreasing. Larger participation seems to increase the potential to provide more benefits. In particular, it increases the chances of spreading the good practices and improving coordination and alignment. The only drawback could be perhaps when organizational units have too diverse practices and strive for more autonomy. In this case, increased participation might lead to increased disagreements.

Other recommendations based on our findings and related research include:

- Enabling decision-making in the community [9, 10, 27, 28];

- Welcoming different level of participation $[10,27]$ to increase the level of participation, as well as the transparency and visibility of community work;

- Allocating the needed resources for community work [22, 27, 28], (members and unit engagement in locally run activities);

- Strengthening external image of the community $[9,10]$, e.g. by making community work results publicly available.

\section{Conclusions}

Several studies show that participation is not only an agile value but is important for any software company to be successful [13]. We have given examples on how a large software company has used corporate-level communities for achieving long-term 
participation across a number of organizational units in enabling alignment and autonomy in large-scale agile organization.

We found communities that had the power to define the strategy, and others that worked with the implementation of a management strategy. Some communities made decisions themselves, others provided recommendations to the management. As such, there were examples of top-down, bottom-up and sandwich decision-making approaches.

We found a number of hindrances that lowered the ability of communities to impact the organizational units. We have listed recommendations for strengthening the communities, with community member selection being the key one to compensate for the common deficiency of mandate given to a community. We conclude that members of parallel structures shall be well-anchored ambassadors, having close contact with practitioners in a selected area, being aware of what is happening across the whole unit, and having a strong network and local authority to deploy the community work.

We will continue to study how both new and old participation techniques are used in Ericsson, and the balance between autonomy and alignment in large-scale agile. We will also study how other large companies can achieve a higher level of participation in agile software development, particularly at the team, project and program level.

\section{References}

1. Moe, N.B., Dingsøyr, T.: Emerging research themes and updated research agenda for largescale agile development: a summary of the 5th international workshop at XP2017. In: Proceedings of the XP2017 Scientific Workshops, p. 14. ACM (2017)

2. Kahkonen, T.: Agile methods for large organizations-building communities of practice. In: Proceedings of the XP Conference, pp. 2-10. IEEE (2004)

3. Olsson, H.H., Bosch, J.: No more bosses? In: Abrahamsson, P., Jedlitschka, A., Nguyen Duc, A., Felderer, M., Amasaki, S., Mikkonen, T. (eds.) PROFES 2016. LNCS, vol. 10027, pp. 86-101. Springer, Cham (2016). https://doi.org/10.1007/978-3-319-49094-6_6

4. Moe, N.B., Aurum, A., Dybå, T.: Challenges of shared decision-making: a multiple case study of agile software development. Inf. Softw. Technol. 54(8), 853-865 (2012)

5. Mintzberg, H.: Mintzberg on Management: Inside Our Strange World of Organizations. The Free Press, New York City (1989)

6. Ingvaldsen, J.A., Rolfsen, M.: Autonomous work groups and the challenge of inter-group coordination. Hum. Relat. 65(7), 861-881 (2012)

7. Takeuchi, H., Nonaka, I.: The new product development game. Harvard Bus. Rev. 64(1), 137-146 (1986)

8. Mohrman, S.A., Edward E.L.: Parallel participation structures. Public Adm. Q. 255-272 (1989)

9. Lawler, E.E., Mohrman, S.A.: Quality circles - after the honeymoon. Organ. Dyn. 15(4), 4254 (1987)

10. Wenger, E., McDermott, R.A., Snyder, W.: Cultivating Communities of Practice: A Guide to Managing Knowledge. Harvard Business Press, Boston (2002)

11. Dybå, T.: An empirical investigation of the key factors for success in software process improvement. IEEE Trans. Softw. Eng. 31(5), 410-424 (2005)

12. Zajac, G., Bruhn, J.G.: The moral context of participation in planned organizational change and learning. Adm. Soc. 30(6), 706-733 (1999) 
13. Moe, N.B., Dybå, T.: Improving by involving: a case study in a small software company. In: Richardson, I., Runeson, P., Messnarz, R. (eds.) EuroSPI 2006. LNCS, vol. 4257, pp. 159170. Springer, Heidelberg (2006). https://doi.org/10.1007/11908562_15

14. Fenton-O'Creevy, M.: Employee involvement and the middle manager: evidence from a survey of organizations. J. Organ. Behav. 19(1), 67-84 (1998)

15. Cotton, J.L., Vollrath, D.A., Froggatt, K.L., Lengnickhall, M.L., Jennings, K.R.: Employee participation - diverse forms and different outcomes. Acad. Manag. Rev. 13(1), 8-22 (1988)

16. Purser, R.E., Cabana, S.: Involve employees at every level of strategic planning. Qual. Prog. 30(5), 66-71 (1997)

17. Baumgartel, H.: Using employee questionnaire results for improving organizations: the survey "feedback" experiment. Kansas Bus. Rev. 12, 2-6 (1959)

18. Guzzo, R.A., Dickson, M.W.: Teams in organizations: recent research on performance and effectiveness. Annu. Rev. Psychol. 47, 307-338 (1996)

19. Dingsøyr, T., Moe, N.B.: The impact of employee participation on the use of an electronic process guide: a longitudinal case study. IEEE Trans. Softw. Eng. 34(2), 212-225 (2008)

20. Dybå, T., Dingsøyr, T., Moe, N.B.: Process Improvement in Practice - A Handbook for IT Companies. Kluwer, Boston (2004)

21. Millen, D.R., Fontaine, M.A.: Improving individual and organizational performance through communities of practice. In: Proceedings of the 2003 International ACM SIGGROUP Conference on Supporting Group Work, pp. 205-211. ACM (2003)

22. Oliver, S., Reddy Kandadi, K.: How to develop knowledge culture in organizations? A multiple case study of large distributed organizations. J. Knowl. Manag. 10(4), 6-24 (2006)

23. Paasivaara, M., Lassenius, C.: Communities of practice in a large distributed agile software development organization-case Ericsson. Inf. Softw. Technol. 56(12), 1556-1577 (2014)

24. Dingsøyr, T., Moe, N.B., Seim, E.A.: Coordinating knowledge work in multiteam programs: findings from a large-scale agile development program. Project Manag. J. 49(6), 1-14 (2018)

25. Moe, N.B., Dingsøyr, T., Rolland, K.: To schedule or not to schedule? An investigation of meetings as an inter-team coordination mechanism in large-scale agile software development. Int. J. Inf. Syst. Proj. Manag. 6(3), 45-59 (2018)

26. Yin, R.K.: Applications of Case Study Research, 2nd edn. Sage Publications, Thousand Oaks (2003)

27. Šmite, D., Moe, N.B., Levinta, G., Marcin, F.: Spotify guilds - cultivating knowledge sharing in large-scale agile organizations. IEEE Softw. 36, 51-57 (2019)

28. Millen, D.R., Fontaine, M.A., Muller, M.J.: Understanding the benefit and costs of communities of practice. Commun. ACM 45(4), 69-73 (2002)

Open Access This chapter is licensed under the terms of the Creative Commons Attribution 4.0 International License (http://creativecommons.org/licenses/by/4.0/), which permits use, sharing, adaptation, distribution and reproduction in any medium or format, as long as you give appropriate credit to the original author(s) and the source, provide a link to the Creative Commons license and indicate if changes were made.

The images or other third party material in this chapter are included in the chapter's Creative Commons license, unless indicated otherwise in a credit line to the material. If material is not included in the chapter's Creative Commons license and your intended use is not permitted by statutory regulation or exceeds the permitted use, you will need to obtain permission directly from the copyright holder.

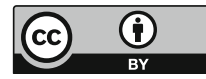

